\title{
A Comparison of the Ability Level of Human Resource Roles and Their Perceived Importance among HR Professionals in the Malaysian Government Linked Companies (GLCs)
}

\author{
Wendy Chan Wai Mei ${ }^{1} \&$ Indra Devi Subramaniam ${ }^{1}$ \\ ${ }^{1}$ Graduate School of Management, Multimedia University, Cyberjaya, Malaysia \\ Correspondence: Indra Devi Subramaniam, Graduate School of Management, Jalan Multimedia, 63100 \\ Cyberjaya, Malaysia. Tel: 60-3-8312-5716. E-mail: indra@mmu.edu.my
}

Received: July 13, 2013 Accepted: August 6, 2014 Online Published: September 29, 2014

doi:10.5539/ass.v10n19p149 URL: http://dx.doi.org/10.5539/ass.v10n19p149

\begin{abstract}
This paper compares the ability level against the perceived importance of the Human Resource roles in the Malaysian government linked companies. The companies comprise of fourteen government linked companies that make up the G20 group of GLCs. These companies were chosen because they contribute to more than $70 \%$ of capitalization of the listed GLCs and have a workforce of nearly 148,000 headcount. Sixty nine HR Managers who were involved in strategic decision making were represented in the study sample. The research design was a correlational study. A structured questionnaire was used to collect data. The questionnaire solicited the perception of the respondents on their ability level of each HR Roles. Four domains of HR Roles were studied: Strategic Partner Role, Change Champion Role, Admin Expert Role and Employee Advocate/Agent Role. The study found that there was a vast difference in their ability level against their perceived importance of the particular HR Role. The mean score for Admin Expert Role was the highest and the Strategic Partner Role was the lowest among the four roles. However, the total effect score showed that the Employee Advocate/Agent Role scored the highest and the Change Champion Role scored the lowest. This juxtaposition suggests that what is actually practiced (ability) is not the same as what is professed (importance). As such it would benefit the HR Managers and their superiors to know that there is a difference in role ability towards role expectations and hence, find ways to improve the performance of the HR Managers and minimize a disparity in role expectation. This will indivertibly increase job performance and satisfaction overall.
\end{abstract}

Keywords: Malaysian Government Linked Companies, HR Roles, performance, perceived ability, perceived importance, HR Managers

\section{Introduction}

With the globalization of businesses and increasing global market competition, investing in human capital is one of the strategies to forge into the future. As such managing this investment requires that the HR professional be equipped to demonstrate an added value of their function to their organization. Thus, they are expected to steer the organization towards organizational growth and competitive advantage (Swanson \& Holton, 2001). Various literatures on HR research have shown a growing interest in the relationship between HRM and performance (Boselie et.al, 2001). The recent trend sees more empirical analysis establishing the competencies and roles which HR professionals need in order to be perceived as strategically contributing towards the growth of the organization (Brewster, 2005; Boselie \& Paauwe, 2004). Some recent studies conducted on organizations situated in the South East Asean region reveal a growing interest in determining the HR architectural fit and effectiveness of HR in contributing a more strategic role (Ahad \& Ghani, 2002; Haslinda et al., 2007; Chew, 2005).

The HR Role, began as an administrative expert tasked to look after the day-to-day operational HR matters. As, the HR profession evolved because of needs, the role moved towards a more strategic partner responsibility where the main role was to devise strategies for the company with other top level managers (De Alwis,2010). However, in the Malaysian scenario, a strategic role for HRM is still a relatively new concept (Rowley \& Saaidah, 2007). The most comprehensive framework on HR Roles (Raub et al., 2006) and which is often used as the benchmark for HR Roles is the one proposed by Ulrich (1997). He developed four main roles of the HR 
professional: Employee Advocate, Administrative Expert, Change Champion and Strategic Partner. The roles are divided into two dimensions: Strategic versus Operational focus and Processes versus People Related. The roles of Administrative Expert and Employee Advocate are operationally focused while Change Champion and Strategic Partner are strategically focused. Within these four roles, Strategic Partner and Admin Expert are people-related while Change Champion and Employee Advocate are processes related. The following diagram shows the four HR Roles.

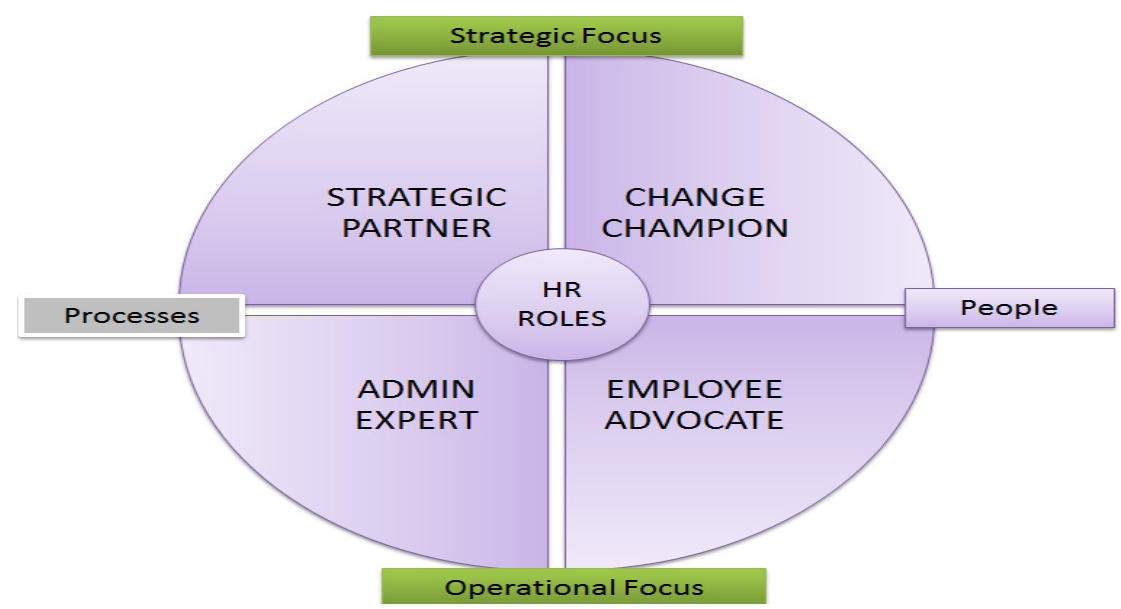

Figure 1. Human resource management four roles model (Source: Conner \& Ulrich, 1996)

\subsection{HR Roles Definition and Factors}

\subsubsection{The role of Strategic Partner}

Guzman et al. (2010) defines the Strategic Partner role as comprising tasks that enhance corporate strategy execution. Lemmergaard (2009) defines this role as a role organized around processes and focuses on procedures that will effectively achieve desired goals. This role is evaluated based on how the HR professional cooperates with the senior and line management to execute overall corporate strategies to achieve organizational goals. . In summary, strategic partner role is owned, directed and used by managers to effectively make HR strategies happen. The link flow from strategic HR enables the transition from business strategy to organizational capability to HR practice (Ulrich \& Eichinger, 1998).

\subsubsection{The role of Change Champion}

This role focuses on people and as Greene (2001), posits, HR is uniquely positioned to take on this role because HR involves people and culture. This role is that of a facilitator, involving a catalyst to change in other departments and across the entire company. The HR professional acts as a Change Champion when they help make change happen by understanding the critical processes for change and building commitment to that process to ensure that change occurs as intended. As described by Lemmergaard (2009), this role creates value by enabling the organization to have the capacity to handle change and that this capacity becomes one of its cultures and is a core competence.

\subsubsection{The role of Administrative Expert}

This role centers on the task of ensuring that traditional HR processes are carried out effectively and efficiently (Ulrich \& Brockbank, 2005). This role requires the design and delivery of efficient HR processes such as staffing, training, appraising, compensation and benefits. The continuous tracking, monitoring and improvement on these processes lend credibility to the existence of the HR function. As Fitz-enz (2000) identified in his study, the Administrative Expertise is still a needed competency and a requirement in the process of moving in the strategic ladder.

\subsubsection{The role of Employee Advocate}

This role requires the HR professional to know the concerns of the employees and uphold their concerns by encouraging various modes of communication such as employee surveys, team meetings, information sharing and etc. Ehrlich (1997) points out that one of the six principles of value creation in HRM is through the role of relationship building and being an outspoken advocate for the employee while having a balance view of business 
needs. As such, the primary role of this relationship building is to create an employee-friendly environment which is committed to the success of the employee's well-being. Buyens \& De Vos (2001) found that the extent to which HR is perceived as a business strategic partner is contingent to the perceived value of this Employee Advocate role within the organization. The key element is to ensure that the employees receive a fair hearing.

\subsection{Theoretical Review}

Increasing volatility and rapid change in the business world has resulted in an emphasis on an alignment of organizational functional activities to the achievement of strategic objectives. One consequence from this emphasis is the call for HR to play a more strategic role (Martell \& Carrol, 1995). Consequently, HR professionals cannot just play the role of "people specialist' in a specialized area of delivering traditional HR services only. They have to widen their influence, be competent in a number of different areas including strategic decision making processes.

HR roles are expressed along two axes: the vertical axes define the dominant focus of HR which is either strategic or operational. Meanwhile, the horizontal axes define the dominant activities of HR which are either process related or people related. The combination of these two axes illustrates four principal HR roles which are Strategic Partner role, Administrative Expert role, Employee Advocate role and Change Champion role.

Through this focus, the HR function will add value to its potential for creating organizational competitiveness (Ulrich, 1997). The adding value by the HR function is based on the creation of competitive advantage, which enables the organization to compete over time. Through building of internal competences aligned to HR practices, the HR function will create essential capabilities that the organization needs to move in this strategic direction (Ulrich et al., 1995). The HR function is able to contribute to the bottom line when the organization changes, learns, moves and acts faster (Ulrich, 1997; Conner \& Ulrich, 1996).

\subsection{The Research Problem}

While HR's transition to more strategic roles has been established in the west (Lawler \& Mohrman, 2003) there is little evidence if Asian HR Professionals have transitioned themselves from the administration role to the multiple roles of strategic partner, change champion and employee advocate (Guzman et al., 2010). Asian firms tend to perceive their HR functions as more traditionally operational and administrative, and not strategic or transformational (Human Resource Asia, 2010). Most Asian organizations view that the role of strategic formulation and execution should be the responsibility of the top management which may not necessarily include HR professionals. However, there are some exceptions in some Asian managers typecasting their HR function in specific non complementing roles. They are either operational or strategic, but not both. They are either people or process oriented, but not both (Human Resource Asia, 2010). The literature review has emphasized the need for HRM to play strategic role for organizational success. In Malaysia, GLCs play an important function in the national economy and contribute substantially to the GDP. The GLC Transformation Initiatives is now in its $4^{\text {th }}$ phase of implementation, which is to reap full National benefit starting from $2010-2015$, the targeted outcomes are: the creation of several regional champions and to shore up the performance of most GLCs to be at par with their competitors. As such, competition for sustainable growth goes beyond doing business locally. The needed human capital will be one of the pillars in the thrust for the $4^{\text {th }}$ phase targets. As such, the purpose of this study is to identify whether there is a match with the ability level of the role that these HR professionals in GLCs are playing now and the perceived importance of that role to the HR function.

\section{Materials and Methods}

The research for this study sought quantitative information about HR managers' roles in their organization. A survey method is used to collect data. The sample used here consists of selected HR professionals from Malaysian GLCs. All the respondents are involved in strategic decision making or strategic roles and activities in one way or another. These companies were chosen because of their substantial contribution to market capitalization and their overall growth earnings which encouraged the overall KLCI market. In terms of manpower, these companies employ over 148 thousand employees. The total number of companies involved in this study is fourteen with sixty nine respondents.

\subsection{Measures of HR Roles}

From the review of literature, the most comprehensive survey instrument for HR Roles is the one developed by Conner \& Ulrich, 1996. This survey was designed to determine the existence and the extent of the four HR Roles outlined by Ulrich (1997) and Conner \& Ulrich (1996). While the original study assessed the levels of ability of these activities, this study added the importance ranking as well. The respondents was asked to rank from 1 to 5 , their perception of their HR department's performance and time spent in the activities, thus reflecting the roles 
that preoccupied the HR department on a daily basis. Since the respondents were involved in the running of the HR function, they effectively were rating their own abilities at the same time too.

The average rankings for the four HR Roles indicated by SPR, AER, AGR and CPR were obtained. The 40 items in the instrument were arranged in groups of four. Each set of four items had a common trend of definition. Each of the four items that were listed corresponded to one of the four roles. Ratings are based on a 5-point Likert scale. The statement for each rating is as follows: $1-2-3-4-5$. The bigger the number is, the higher the rating.

The pilot study was to measure and try to reduce measurement error. If the measurement error is reduced, the reliability of the measurement technique is increased (Frey et.al., 2000). Therefore, the pilot study using the Cronbach alpha coefficient method was used for this purpose. The result of the reliability test of HR Roles instrument shows that the alpha value base in each domain of the instrument is between $0.83-0.94$. The components that were tested were: Strategic Partner Role (alpha value $=0.94)$, Administrative Expert Role (alpha value $=0.89)$, Employee Advocate Role (alpha value $=0.83)$ and Change Champion Role (alpha value $=$ 0.94). According to Litwin (1995), Cronbach alpha value of more than 0.7 is acceptable for measuring the reliability of the questionnaire items. Frey et.al (2000) posits that the measurement instrument can be considered reliable if the reliability value is 0.70 or greater. Therefore, from the alpha value obtained, we can conclude that the research instrument is reliable and consistent.

\subsection{Data Collection}

Sourcing of data from these managers was done in either three ways or a combination of any two. The first method was done by sending the paper based version by email (in words format) to the designated manager. Follow up was done after one week to remind the manager if they had not returned the survey via email. A second reminder would be done the following week via email again. Usually the managers would respond by the second reminder. There were some, however, who responded after the third reminder which was carried out via telephone.

The second method was meeting the designated manager face to face. Earlier preparations of securing an appointment would have been arranged a few weeks before the appointment. The researcher endeavored to arrange as many appointments as possible that could be conducted in each company. Usually two appointments would suffice for each appointment. During the face to face meeting, the designated manager would usually oblige to answer the survey right there and then with the assistance of the researcher to explain some of the required questions. There were some instances whereby the manager concerned was not able to answer the survey immediately, so a return-mail envelope was made available for the designated manager. A follow-up call was made if the designated manager had not returned the envelope by ten (10) working days.

The third method was using the online version. When method one and two was not sufficient to garner responses from the designated manager, an online version was sent to the designated manager's email. Then the researcher would follow-up with a telephone call or an email to encourage the designated manager to fill up the online version. A cutoff date is given, usually three (3) weeks for the designated manager to log into the online version. After the cutoff date, if the designated manager had not responded to the survey, a follow-up call would suffice.

The researcher did not encounter too many non-responding respondents as the senior HR person would usually assign one personnel/manager to follow up with the researcher. The researcher ensured that the personnel/manager assigned was always updated of the progress of data collection in that particular company.

\subsection{Data Analysis}

The data was analyzed using the Partial Least Squares Structural Equation Modeling (PLS-SEM). The PLS-SEM approach, which is an alternative technique for SEM, has lately become a key research method because of its distinctive methodological features (Hair, Sarstedt, Ringle, \& Mena, 2012). Specifically, PLS-SEM has several advantages. It is used when sample sizes are small, data are non-normally distributed or when complex models with many indicators and model relationship estimation arises (Hair, Ringle, \& Sarstedt, 2011).

There are three stages to prepare when using the PLS-SEM approach. The stages are: specifying the structural model, selecting the measurement model and examining the collected data to ensure the results from applying PLS-SEM are valid and reliable. For the analysis, each participant's ratings for HR roles domains were summed up to obtain the total for each role segment. The summation would indicate which HR role the participant had a strongest inclination towards, i.e.: the strongest HR role would mean the role that preoccupied the daily HR function. In addition, they were asked to rate the four HR Roles on the importance to their HR function. An exploratory factor analysis (EFA) was performed to determine if common method variance was a problem. 
Common method variance usually occurs when data is sourced from a single source (Liang et.al. 2007). All the measurement items were entered into the SPSS analysis and the results showed that the largest variance explained by an individual factor was $34.1 \%$ (less than $50 \%$ ). This shows that neither a single factor nor a general factor accounted for the majority of the covariance measured. Thus, this indicates that common method bias is not a significant problem for the current study.

\section{Results}

Table 1. Sum and mean score of each HR roles domain

\begin{tabular}{lllll}
\hline HR Role & N & Mean & Sum & Rank \\
\hline Admin Expert Role (AER) & 69 & 4.003 & 2762 & $1^{\text {st }}$ \\
Employee Agent/Advocate Role (AGR) & 69 & 3.919 & 2704 & $2^{\text {nd }}$ \\
Change Champion Role (CPR) & 69 & 3.906 & 2695 & $3^{\text {rd }}$ \\
Strategic Partner Role (SPR) & 69 & 3.807 & 2627 & $4^{\text {th }}$ \\
\hline
\end{tabular}

Table 1 shows the highest sum and mean score of HR Roles is from the Admin Expert Role (AER). It obtained a sum score of 2762 out of a maximum score of 3450 (10 items x 5 pints of maximum score per item x 69 respondents). It has the highest mean score per item of 4.003 out of a mean score of 5.0 (5 points of maximum score per item). The Employee Advocate Role ranked second with a sum score of 2704 and a mean score of 3.919. The Change Champion Role is ranked third with a sum score of 2695 and a mean score of 3.906. And lastly, the Strategic Partner Role is ranked last with a sum score of 2627 and a mean score of 3.807 out of 5.0. These findings are similar with the study done by Choi \& Wan Khairuzzaman (2008) on 32 HR professionals from the manufacturing sector. In addition, these findings concur with Conner \& Ulrich (1996) study, whereby, the scores are higher for the Employee Advocate and Admin Expert Roles as compared to the Change Champion and Strategic Partner Roles. This suggests that the HR function is more focused on playing a day-to-day operational role than in a strategic role. These findings are also supported by Raub et.al. (2006) study which identified the time spent on roles and in decision making involvement. That study found that unit level managers in the hospitality sector focused more on their administrative and employee advocate roles. The results of this study provide evidence that there is a lack of emphasis on the Strategic Role of the HR professional. Generally, HR professionals do not have the opportunity to play a more strategic or change agent roles because they are preoccupied with their administrative role on a daily basis.

Table 2. Importance of each HR Roles domain

\begin{tabular}{lccc}
\hline \multicolumn{1}{c}{ HR Roles } & N & Importance (Total effects) & Rank \\
\hline Employee Agent /Advocate Role (AGR) & 69 & 0.448 & $1^{\text {st }}$ \\
Strategic Partner Role (SPR) & 69 & 0.292 & $2^{\text {nd }}$ \\
Administrative Expert Role (AER) & 69 & 0.191 & $3^{\text {rd }}$ \\
Change Champion Role (CPR) & 69 & 0.089 & $4^{\text {th }}$ \\
\hline
\end{tabular}

Table 2 shows the total effects score of each HR Roles domain. The total effects are interpreted as the score for the importance ranking of the HR Role. The IPMA-PLS-SEM extends these results to identify the importance of each construct (Hair et. al., 2014). IPMA stands for Importance-Performance Matrix Analysis. Analysis from the study shows that the HR Professional deem the Employee Agent /Advocate Role as the most important role among the four roles. This is followed by the Strategic Partner Role. The Administrative Expert and Change Champion Role rank lower than the Strategic Partner Role. In De Alwis (2010) study, it was found that the HR professionals played differing roles after the introduction of e-HR. Prior to the introduction of e-HR, the HR professionals were playing the roles as shown in Table 1, with the Admin Expert Role predominantly permeating the HR function. After the implementation of e-HR, the same HR professionals began to take on the Roles more akin to those as shown in Table 2.

However, in this case, the Strategic Partner Role predominantly permeated the HR function. De Alwis (2010) further suggests that this shift may be due to the fact that the HR professional had more time to concentrate on being strategic when operational HR functions are aided by high speed effective management tools (e-HR). Thus, it reduces the administrative burden of the HR department. Kathri's (2002) study found that the HR Managers interviewed identified some HR activities that could be outsourced so that they could spend more time on strategic function. Among the activities proposed to be outsourced were administrative mundane activities, 
recruitment and training of certain sectors of the workforce. Again, these findings concur with the results in Table 2 on what HR Roles the HR professionals in GLCs deem as important.

Guzman et al (2010) study on the permeability of the HR Roles among Asian HR professionals suggests why the HR professional were unable to shift roles between the strategic focused roles (Strategic Partner \& Change Champion Roles) and operational focused roles (Admin Expert \& Employee Agent Roles). This condition in which Ulrich (1996) calls 'the inherent paradox for execution' may explain the difference in perception of the ability and the importance of the HR Roles domains. The HR professional is part of the management team because he has to be a strategic partner to the company. However, on the other extreme, being a part of the management team alienates employees from both the HR and the management. As Employee Agent/Advocate, HR professionals ensure that the concerns and needs of the employees are voiced to the management, thus, giving the employees a fair deal. However, the top management may see that the HR professional is insensitive to business realities and thus cause a conflict in interest. This tension between roles causes an execution paradox and must be managed effectively by the HR professional in order to find a balance in the HR function.

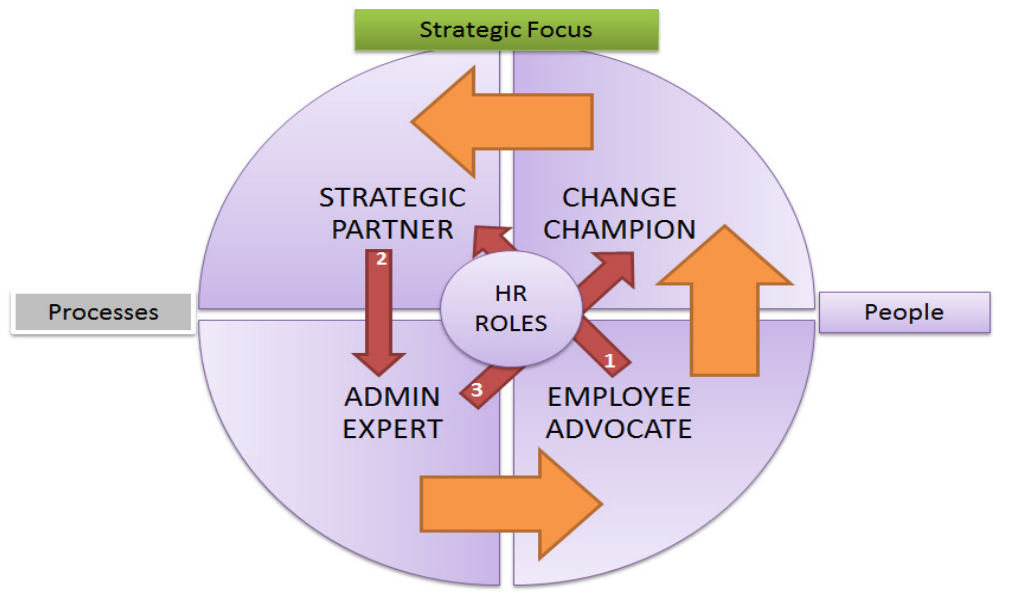

Figure 2. Direction of the HR Roles-Ability versus the HR Roles-Importance

* The broad orange arrows show the direction of the ability/ performance of the HR Roles. The red arrows show the direction of the important HR Roles.

The findings of Table 1 and Table 2 and diagram 2 suggest that there is a shift in Roles when an external factor, for example, e-HR such as in the case of De Alwis (2010), outsourcing as in the case of Kathri \& Budhwar (2002) and execution paradox as suggested in Guzman et al. (2010) is introduced. It is also possible that the importance ranking is influenced by what the HR Professionals perceive they should be spending more time on, thus, it is a more important role to concentrate on.

\subsection{Theoretical Implications}

Studies on the roles of HR professionals have found that organizations still lack in acknowledging the strategic partner role as the primary role of the HR professional (Wright, McMahan, Snell \& Gerhart, (2001). Subsequently, this gives rise to the mismatch of expectations of the HR professional being a strategic partner (Raub, Alvarez \& Khanna, 2006; Wright et al., 2001). For example, in the study conducted by Raub et.al, (2006), it was found that the HR professionals identified the employee champion and administrative expert roles as their primary responsibilities rather than the strategic partner role. Conner \& Ulrich (1996) found that the line managers rated the HR professionals in their organization as having the lowest score on strategic partner. Similarly, Booselie \& Paauwe (2005) found that the strategic contribution of the HR professional is a necessary precondition for improving financial competitiveness of an organization. In their study, it was found that the majority of the HR professionals were not playing a strategic role.

The US, Human Resource Institute (HRI) found in their study in 2002, that the roles of HR Professionals had evolved and become better defined as compared to when they did a similar study in 1998. In 1998, they reported that the primary role of the HR Professional was that of a functional expert. However, in their 2002 version of 'The Role and Structure of Human Resources' survey, they found that being a business partner and a strategic thinker was more important than functional expertise. They summed that HR professionals now were 
progressing in assuming roles that add more value to the organization. These arguments led us to conclude that there was a possibility of an existing gap between the role that is present (ability) and the role that is important which was proven by the results of the analysis.

\subsection{Managerial Implications}

The study suggests that HR Managers need to align the perception of what HR role is important to their organization and to the role that they playing now. This allows for the (re) alignment of the organizational business needs and leadership development. The process of organizational realignment helps the organization to access what they have now and what they need next to bring the business to the next level (Yong, 2005). HR Managers need to know where they stand in their role contribution. Thus, allowing HR functions to evolve to SHR initiatives. When there are SHR initiatives, the HR department can now begin to drive business needs and develop leadership.

When this gap of perceived importance and present ability is bridged closer, the HR professional will not just have a 'seat at the strategic table' but begin to contribute in a more visible manner. In addition, HR professionals will be able to see where they need to concentrate in order to approach their vocation in a specialist manner. In supporting this approach, Kathri \& Budhwar (2002) say that the top management needs to know and acknowledge that the HR function must be managed by professionally qualified HR people and they (the top management) cannot ignore the growing technical and analytical sophistication that is expected of the HR professional especially so where the HR Managers are required to play a strategic role. Kathri (2000) posit that pursuing a non-specialist and pro-generalist path may turn out to be counterproductive in the long haul. Therefore, Malaysian GLC HR professionals should pay attention to Table 2 and gap their present performance of Table 1 to align more to Table 2. This can be done with the introduction of external factors such as effective technological initiatives and improvement (De Alwis, 2010), efficiency of intra-company communication policies (Nyanga, 2006) and more empowerment and attitude change of the HR professional (Wood, 2000).

\subsection{Summary}

The results from this study provide evidence that the HR Managers in the selected GLCs are still not playing a strategic HR Role. They are more preoccupied with their Administrative function. As such, they are not seen to be contributing at the strategic table.

\section{Conclusion}

HR professionals in the GLCs showed that there was a difference in the ability of the HR Roles that they played to the perceived important roles. There is a need to bridge this gap closer so that the HR professional is not just having a 'seat at the strategic table' but begin to contribute in a more visible manner. In addition, HR professionals need to approach their vocation in a specialist manner. In supporting this approach, Kathri \& Budhwar (2002) say that the top management needs to know and acknowledge that the HR function must be managed by professionally qualified HR people and they (the top management) cannot ignore the growing technical and analytical sophistication that is expected of the HR professional especially so where the HR Managers are required to play a strategic role. Kathri (2000) posit that pursuing a non-specialist and pro-generalist path may turn out to be counterproductive in the long haul. Therefore, Malaysian GLC HR professionals should pay attention to Table 2 and gap their present performance of Table 1 to align more to Table 2. This can be done with the introduction of external factors such as effective technological initiatives and improvement (De Alwis, 2010), efficiency of intra-company communication policies (Nyanga, 2006) and more empowerment and attitude change of the HR professional (Wood, 2000).

\section{Limitations and Recommendations}

All the results explained and discussed have to be interpreted in the light of the following limitations.

Firstly, generalization of the study results is limited only to the HR Managers of the selected Malaysian GLCs. As such, transference to other population has to be treated with caution. Further research on the HR link to GLCs should be pursued since HR is becoming more strategic and what better place to spearhead a transformation in none other than Government Led Transformation (GLT) companies.

Secondly, the number of respondents was limited in number. The limitation on low variance of the main variables could mean that responses from those who are highly interested in Strategic HRM or those who were assigned by their superiors could cause an unequal representation of HR Managers. The researcher endeavored to obtain as many responses as possible given that some respondents felt that they were not at liberty to divulge their views unless directed by their superiors. Thus, subsequent studies can concentrate on increasing the number of participants to include the perceptions from Line Mangers too. 
Thirdly, this study applied the common method variance of using a single source for the investigation of all the variables. However, an exploratory factor analysis (EFA) was carried out and obtained an individual factor of $34.1 \%$ (less than $50 \%$ ). As such, common method bias is not a problem in this study. However, in order to minimize this type of biasness, further research can be carried out to obtain a comparative perception from both the HR Managers and the non HR Managers of the GLCs.

Finally, this study is a cross-sectional study where data are collected at only one point of time. Future research could concentrate on a limited number of companies but for a longer period of time-observation in order to establish if there is causality between the variables.

\section{References}

Ahad, A., \& Osman Ghani, M. (2002). HRD Competencies for Effective Performance in Knowledge Based Economy: A study of HRD professionals in Singapore. Conference Proceedings in Academy of HRD (AHRD) Symposium. Honolulu Hawaii, Feb 27 - March 3, 2002. Report No.6, 19-26. http://dx.doi.org/10.1177/ 1523422304266074

Haslinda, A., Rose, R. C., \& Kumar, N. (2007). HRD Strategies: The Malaysian Scenario. Journal of Social Science, 3(4), 213-222. http://dx.doi.org/10.3844/jssp.2007.213.222

Booselie, P., \& Paauwe, J. (2005). Human Resource Function competencies in European companies. Personnel Review, 34, 550-566. http://dx.doi.org/10.1108/00483480510612512

Boselie, P., Paauwe, J., \& Jansen, P. (2001). Human resource management and performance: Lessons from the Netherlands. The International Journal of Human Resource Management, 12(7), 1107-1125.

Boselie, P., \& Paauwe, J. (2004). HR Function Competencies in European Communities. ERIM Report Series Research in Management, 1-31. http://dx.doi.org/10.1177/1523422304266074ERS-2004-069-ORG.

Brewster, C. (2005). The Configurational Approach to Linking SHRM Bundles with Business Performance: Myth or Reality. Management Revue, January, 2005.

Buyens, D., \& De Vos, A. (2001). Perceptions of the value of the HR function. Human Resource Management, 11(3), 70-89. http://dx.doi.org/10.1111/j.1748-8583.2001.tb00046.x

Chew, Y. T. (2005). Achieving Organisational Prosperity through Employee Motivation and Retention: A Comparative Study of Strategic HRM Practices in Malaysian Institutions. Research and Practice in Human Resource Management, 13(2), 87-104.

Long, C. S., \& Khairuzzaman, W. (2008). Understanding the relationship of HR competencies \& Roles of Malaysian HR Professionals. European Journal of Social Sciences, 7(1), 88-103.

Conner, J., \& Ulrich, D. (1996). Human Resource Roles: Creating Value, not Rhetoric. Human Resource Planning, 19(3), 38-49.

De Alwis, A. C. (2010). The impact of electronic HRM on the role of HR Managers. E+M Ekonomie a Management, 4, 47-60. Retrieved from http://www.readperiodicals.com/201010/2219425941.html.

Ehrlich, C. J. (1997). Human Resource Management: A Changing Script for a Changing World. Human Resource Management, 36(1), 85-90.

Fitz-enz, J. (2000). The ROI of Human Capital. Measuring the Economic Value of Employee Performance. New York. American Management Assoc (AMACOM).

Frey, L. R., Botan, B. H., \& Kreps, G. L. (2000). Investigating Communication: An Introduction to Research Methods. Allyn \& Bacon, Boston.

Greene, R. J. (2001). Effectively managing Intellectual Capital: Critical Challenge for Human Resources. SHRM White Papers. Retrieved July 12, 2010, from http://www.shrm.org./whitepapers/documents/default.asp? page $=61151$.asp

Guzman, G. M., Lim, R. A., \& Briones, D. T. (2010). The permeability of HR roles. Asia Academy of Management Conference .AIM working paper series 10-001. Retrieved June 24, 2012, from http://www.aim.edu/aim_images/pdf

Hair, J. F., Hult, G. T. M., Ringle, C. M., \& Sarstedt, M. (2014). A Primer on Partial Least Squares Structural Equation Modeling (PLS-SEM). Sage. London.

Hair, J. F., Ringle, C. M., \& Sarstedt, M. (2011). PLS-SEM: Indeed a silver bullet. Journal of Marketing Theory and Practice, 19, 139-151. http://dx.doi.org/10.2753/MTP1069-6679190202. 
Hair, J. F., Sarstedt, M., Ringle, C. M., \& Mena, J. A. (2012). An assessment of the use of partial least squares structural equation modeling in strategic management research: A review of past practices and recommendations for future applications. Long Range Planning, 45, 320-340. http://dx.doi.org/10.1016/j.lrp.2012.09.008

HR Institute. (2002). The Role \& Structure of Human Resources. Survey. 2002 Version.

Human Resource Asia. (2010). Top 5 HR Challenges for 2010. Human Resource Asia. Retrieved June 20, 2012 , from http://Hrmasia.com/resources/strategic-hr/top-5-hr-challenges-for-2010/39421

Khatri, N. (2000). Managing human resource for competitive edge: A study of companies in Singapore. The International Journal of Human Resource Management, 11(2), 336-65. http://dx.doi.org/10.1080/09585 1900339909

Khatri, N., \& Budhwar, P. S. (2002). A study of strategic HR issues in an Asian context. Personnel Review, 31(2), 166-188. http://dx.doi.org/10.1108/00483480210416856

Lawler, E. E., \& Mohrman, A. M. (2003). Creating a strategic human resource organization: An assessment of trends and new directions. Stanford, CA: Stanford University Press.

Lemmergaard, J. (2009). From administrative expert to strategic partner. Employee Relations, 31(2), $182-196$. http://dx.doi.org/10.1108/01425450910925328

Liang, H., Saraf, N., Hu, Q., \& Xue, Y. (2007). Assimilation of enterprise systems: The effect of institutional pressures and the meditating role of top management. MIS Quarterly, 31(1), 59-87.

Martell, K., \& Carrol, S. (1995). How Strategic is HRM? Human Resource Management, 34(2), 253-267.

Nyanga, T. (2006). Reliance Holdings Job Evaluations Report. Company Report. Zimbabwe, Bulawayo.

Raub, S., Alvarez, L., \& Rahul, K. (2006). The different roles of corporate and Unit level HR Managers in the hospitality Industry. International Journal of Contemporary Hospitality management, 18(2), 135-144. http://dx.doi.org/10.1108/09596110610646682

Rowley, C., \& Saaidah, A. R. (2007). The Management of HR in Malaysia: Locally owned Companies \& Multinational Companies. Management Review, 18(4), 427-453. Retrieved from http://hdl.handle.net/ $10419 / 78917$

Swanson, R. A., \& Holton, E. F. III. (2001). Foundations of Human Resource Development. San Francisco: Berrett-Koehler.

Ulrich, D., \& Eichinger, R. (1998). Delivering HR with an attitude. HR Magazine.

Ulrich, D., Brockbank, W., Yeung, A. K., \& Lake, D. G. (1995). Human resource competencies: An empirical assessment. Human Resource Management, 34(4), 473-492.

Ulrich, D., \& Brockbank, W. (2005). HR's New Mandate: Be a Strategic Player. The HR Value Proposition. Harvard Business School Press. Boston, MA, 898-925.

Ulrich, D. (1997). HR Roles: Business Partners Whose time has come. In I. H. Risher, \& C. Fay (Eds.), The future of Human Resource Management.

Wood, W. (2000). Attitude change: Persuasion and social influence. Annual Review of Psychology, 51, 539-570. http://dx.doi.org/10.1146/annurev.psych.51.1.539.

Yong, A. (2005). Strategic HR: Invent \& Innovate. Genuine Circuit Sdn Bhd, Kuala Lumpur.

\section{Copyrights}

Copyright for this article is retained by the author(s), with first publication rights granted to the journal.

This is an open-access article distributed under the terms and conditions of the Creative Commons Attribution license (http://creativecommons.org/licenses/by/3.0/). 